\title{
STROKE MANAGEMENT IN A UNIVERSITY HOSPITAL IN THE LARGEST SOUTH AMERICAN CITY
}

\author{
Adriana Bastos Conforto', Rodrigo Bomeny de Paulo², Cristiane Borges Patroclo3, \\ Samira Luísa dos Apóstolos Pereira ${ }^{3}$. Helder de Souza Miyahara², Camila Barião da Fonseca², \\ Fabio luji Yamamoto ${ }^{3}$, Paulo Eurípides Marchiori ${ }^{4}$, Eli Faria Evaristo ${ }^{5}$, Milberto Scaff
}

\begin{abstract}
Objective: To describe characteristics and provision of care for patients admitted with cerebrovascular disorders (CVD), focusing on ischemic stroke (IS), in a large, public, academic hospital in São Paulo, Brazil. Method: We retrieved information about 357 patients with CVD admitted to the Neurology Emergency Department (NED) and Neurology Ward (NW) of our institution. We described patient characteristics and management of IS in NED and in NW. Results: IS was diagnosed in 79.6\% of CVD patients admitted to NED; $2.7 \%$ were submitted to thrombolysis. Extent of IS investigation and management were significantly different in NED and NW. Conclusion: IS patients in our center were younger than in developed countries. IS management was significantly influenced by patient characteristics. This information can aid in planning strategies to decrease stroke burden.
\end{abstract}

KEY WORDS: stroke, diagnosis, thrombolytic therapy, emergency treatment.

\section{Manejo do acidente vascular cerebral em um hospital universitário na maior cidade da América do Sul}

Resumo - Objetivo: Descrever características e manejo de pacientes internados com diagnóstico de doença cerebrovascular (DCV), enfocando principalmente o acidente vascular cerebral isquêmico (AVCI), em um hospital público universitário em São Paulo. Método: Coletamos informações de 357 pacientes com DCV internados no Pronto-Socorro de Neurologia (PSN) e na Enfermaria de Neurologia (EN) de nossa instituição. Descrevemos características dos pacientes e manejo do AVCI no PSN e na EN. Resultados: O AVCI foi diagnosticado em 79,6\% dos pacientes com DCV admitidos no PSN; 2,7\% foram submetidos a trombólise. A extensão da investigação e o manejo da doença foram significativamente diferentes no PSN e na EN. Conclusão: Os pacientes com $\mathrm{AVCl}$ em nosso centro foram mais jovens que em países desenvolvidos. O manejo do $\mathrm{AVCl}$ foi influenciado significativamente pelas características dos pacientes. Estas informações podem auxiliar no planejamento de estratégias para diminuir as conseqüências das DCV em nosso meio.

PALAVRAS-CHAVE: acidente cerebrovascular, diagnóstico, terapia trombolítica, tratamento de emergência.

It has been estimated that two thirds of stroke patients live in low-income and middle-income countries ${ }^{1}$. Stroke will be an epidemic in South America over the next decades in association with demographic changes of the population, progressive urbanization and changes in lifestyle. In order to implement effective health policies, it is crucial to know how stroke care is currently provided but there is a gap in information about stroke management in the continent ${ }^{2,3}$.
Stroke is a leading cause of mortality in Brazil and ageadjusted mortality rates for stroke are higher than in other South American countries ${ }^{4-6}$. São Paulo is the largest city in South America. In 2004, it was estimated that 19,128,164 people lived in the urban São Paulo metropolitan area ${ }^{7}$. Cerebrovascular disease was a common cause of overall mortality, second only to ischemic heart disease ${ }^{4}$.

Our goals were to describe characteristics and provision of care for patients admitted with cerebrovascular

\footnotetext{
This study was performed in the Neurology Department, Clinics Hospital/São Paulo University, São Paulo SP, Brazil: 'MD, PhD. Neurology Division, Clinics Hospital/São Paulo University and Instituto do Cérebro, Instituto de Ensino e Pesquisa, Hospital Israelita Albert Einstein, São Paulo SP, Brazil; ${ }^{2} \mathrm{MD}$, São Paulo University Medical School; ${ }^{3} \mathrm{MD}$, Neurology Division, Clinics Hospital/São Paulo University; ${ }^{4} \mathrm{MD}$, PhD, Associate Professor, Neurology Department, Clinics Hospital/ São Paulo University; ${ }^{5} \mathrm{MD}$, PhD, Neurology Division, Clinics Hospital/São Paulo University; ${ }^{6} \mathrm{MD}$, PhD, Chief Professor, Neurology Department, Clinics Hospital/São Paulo University. Financial support: Rodrigo Bomeny de Paulo received a scholarship for medical students provided by Programa Institucional de Bolsas de Iniciação Científica/Conselho Nacional de Desenvolvimento Científico e Tecnológico (PIBIC - Institucional Usp), grant Usp 2006.1.36948.1.0.
}

Received 30 January 2008, received in final form 12 April 2008. Accepted 26 April 2008.

Dra. Adriana Bastos Conforto - Neurology Division / Clinics Hospital / São Paulo University - Avenida Dr. Enéas C. Aguiar 255/5084 - 05403-000 São Paulo SP - Brasil.E-mail: abconf@yahoo.com, abconf@usp.br 
diseases (CVD), focusing on ischemic stroke (IS), in a large public, academic hospital in São Paulo.

\section{METHOD}

We retrospectively evaluated hospital records of $357 \mathrm{pa-}$ tients aged $>15$ years, consecutively admitted with a diagnosis of acute stroke event or transient ischemic attack (TIA) in the Neurology Emergency Department (NED) between September $1^{\text {st }}$ and December ${ }^{\text {st }}, 2004$, and in the Neurology Ward (NW), between November $1^{\text {st }}, 2003$ and November $1^{\text {st }}, 2005$. The local Ethics Committee approved the study and the procedures followed were in accordance with institutional guidelines. Neurologists and a CT scanner were available on-site in the Neurology Emergency Department (NED), 24-hours a day, 365 days per year. The entire hospital had 3000 beds, 20 of them dedicated to Neurology patients. Patients with a diagnosis of IS were typically either discharged home from the NED, or were referred to ICUs or the general Neurology Ward (NW). Discharge home, from NED, was made at the discretion of the neurologist in charge; usually, patients were discharged if there were no need of intensive care, and no decrease in level of consciousness (LOC), in the presence of a stable neurological status. If these criteria were fulfilled and beds were available, patients were admitted to NW. Patients admitted to the NW, but not patients admitted exclusively to the NED, were routinely referred to outpatient followup in our institution.

A total of 186 patients were admitted within the threemonth period and the diagnosis was IS in 148 (79.6\%) patients. We also reviewed information from 191 patients admitted with a diagnosis of acute IS or TIA in the NW in the two-year period. Identical standardized forms were used to abstract data from medical files of all patients: demographic characteristics, history of arterial hypertension, history of previous stroke or TIA, performance of thrombolysis, source of referral of patients, interval between time of symptom onset (or last time the patient was seen well) and NED admission, and performance of diagnostic procedures. Scales of stroke severity, such as the NIH Stroke Scale, were not applied routinely to stroke patients not submitted to thrombolysis in the NED in our institution. Therefore, we considered LOC as a surrogate of stroke severity. Data about LOC was available in medical charts, in the description of the neurological examination, either as "normal" or "abnormal" (disorientation, confusion or decrease in LOC), for 81.5\% ( $N=104$ ) of patients admitted to the NED only, and for $100 \%$ from those admitted to both NED and NW (N=191). In the regression logistic analysis, only data from patients with known LOC at admission were included $(n=295)$.

The percentage of patients admitted to the NED and also to the NW between September $1^{\text {st }}$ and December $1^{\text {st }}$ was calculated. In addition, we compared characteristics and extent of investigation (neuroimaging studies or echocardiogram) from patients admitted to the NED only (three-month period), and patients admitted to both NED and NW (two-year period).
Normality of the data was checked with the KolmogorovSmirnov test. Results are given as mean \pm standard deviation for data with normal distribution. For univariable analyses, the Mann-Whitney test was used to compare ages and lengths of stay of IS patients admitted to NED only or to NED and NW. Chi-square tests were used to compare categorical variables of patients from the two groups. Age, gender, ethnicity, history of arterial hypertension, history of previous stroke or TIA, performance of thrombolysis and LOC at admission were included in a binary logistic regression model having patient admission as the dependent variable, dichotomized into "NED only" or "NED and NW". Minitab 14.0 and SPSS 10.0 for Windows were used for statistical analysis.

\section{RESULTS}

The average age of CVD patients admitted to the NED ( $n=186)$ was $65.3 \pm 14.8 ; 57 \%$ of them were male. IS was diagnosed in $79.6 \%$ patients, hemorrhagic strokes in $13.4 \%$, TIAs in $2.7 \%$, cerebral venous thrombosis in $0.5 \%$; type of stroke was undetermined in $3.8 \%$. Mean age of IS patients ( $n=148$ ) was $66.4 \pm 14.1$ years. Only $10.8 \%$ of IS patients arrived up to three hours from symptom onset; $2.7 \%$ of the all patients, or $25 \%$ of patients who arrived within 3 hours were treated with intravenous thrombolysis.

A total of $20 / 148$ (13.5\%) IS patients from the NED were admitted to the NW within the three-month period. The Table shows characteristics of patients admitted only to the NED only within this period and those of patients admitted to both NED and NW during the two-year period. Median length of stay of IS patients in NED was 2 days (range, hours to 48 days) and in NW, 14 days (1-141 days). Differences in lengths of stay were significant $(p<0.001)$.

LOC was normal in $73 \%$ of those admitted to NED only and in $78.5 \%$ of those admitted to NED and NW. Binary logistic regression showed that patients admitted to the NW were less likely to be old (OR 0.92-0.96; $p<0.001$ ), have previous history of stroke or TIA (OR 0.18-0.74; $p=0.005$ ) and were more likely to have received thrombolysis (OR 1.94-154.0; $p=0.011$ ) and have presented normal level of consciousness at admission (OR 1.36-7.30; p=0.008). Gender, ethnicity and history of arterial hypertension were not significantly different across the two groups of patients ( $p>0.05)$.

Head CT was done in $100 \%$ of patients admitted to the NED or to the NW. Performance of other neuroimaging studies or echocardiogram was significantly higher in patients admitted to the NED and NW (99.4\%) than in those admitted only to the NED (35.1\%) $\left(\chi^{2}=163.5, \mathrm{p}<0.001\right)$.

\section{DISCUSSION}

Patients with stroke admitted to the NED were, on average, one decade younger than those of other hospitalbased series in developed countries. Often, hospital-based 
Table. Characteristics of patients admitted to the Neurology Emergency Department (NED) only, from September $7^{\text {st }}$ to December $7^{5 t}, 2004$, and of patients admitted to both the NED and the Neurology Ward (NW) from November 7t, 2003 to November 7 $7^{\text {st }}, 2005$.

\begin{tabular}{lccc}
\hline Characteristics & NED only & NED and NW & p value \\
\hline Age (mean \pm sdv) & $67.7 \pm 13.2$ y & $53.5 \pm 16.4$ y & $<0.001$ \\
Gender & & & \\
Male & $53.9(69)$ & $62.3(119)$ & 0.135 \\
Female & $43.1(59)$ & $37.7(72)$ & \\
Ethnicity & & & 0.83 \\
White & $78.9(105)$ & $78.5(150)$ & \\
Non-white & $19.5(25)$ & $21.0(40)$ & \\
Undetermined & $1.6(2)$ & $0.5(1)$ & $<0.001$ \\
History of AH & & & \\
Yes & $80.5(103)$ & $59.7(114)$ & \\
No & $11.7(15)$ & $38.7(74)$ & \\
Unknown & $7.8(10)$ & $1.6(3)$ & \\
Previous stroke or TIA & & $12.0(23)$ & \\
Yes & $32.0(41)$ & $88.0(168)$ & \\
No/Unknown & $68.0(87)$ & $5.8(11)$ & 0.063 \\
Thrombolysis & $1.6(2)$ & $94.2(180)$ & \\
Yes & $98.4(126)$ & & \\
No & & & \\
\hline
\end{tabular}

$\mathrm{AH}$, arterial hypertension; TIA, transient ischemic attack.

stroke registers are biased toward younger patients with more severe strokes ${ }^{8}$. However, similar findings were reported in developing countries in other continents in the STEPS study', in a community and hospital-based study carried out in Southern Brazil a decade ago', in a recent population-based study in a smaller Brazilian city ${ }^{10}$, and in the PISCIS project, a comprehensive epidemiological study in an isolated geographically area in Chile ${ }^{6}$. Therefore, heavy burdens on families, society and health systems are to be expected.

The overall thrombolysis rate in patients admitted to the NED was similar to those of community-based stroke studies in developed countries, but lower than those of reference stroke centers ${ }^{11,12}$. Thrombolysis was feasible but, as in other parts of the world, measures to increase treatment rates are necessary.

Even though important tools for stroke diagnosis (neurological evaluation, $\mathrm{CT}$ ) were widely available for all patients, there were striking differences between patient characteristics and definition of stroke etiology in NED and in NW. Neurovascular work-up was the rule in the NW, but was restricted to about a third of patients admitted exclusively to the NED. Patient profile can influence stroke management: other studies have described lower rates of diagnostic work-up in the elderly ${ }^{13}$ and in women in countries of varied income levels ${ }^{1,14}$. In our hospital, younger age, thrombolytic treatment, normal LOC at admission and first-ever-in-a-lifetime strokes were characteristics significantly more likely to be present in patients who were admitted to the NW and were submitted to inpatient investigation, than to those who were not. These differences are partially explained by institutional policies: first, the main goal in the NED is to provide IS emergency support and not, IS investigation; second, patients submitted to thrombolysis are necessarily referred to ICUs and then, to the NW; third, admission criteria to the NW include clinical stability. It is reasonable that LOC will not be affected in most of neurologically stable stroke patients. Still, as in other studies, older patients and patients with recurrent strokes were less frequently admitted to the NW, even after adjustment for stroke severity, indirectly evaluated by LOC.

This study has some limitations: it was retrospective and LOC was used as a surrogate of stroke severity. However, research capability in developing countries often limits prospective studies and retrospective investigations can then provide important information to help clarify the status of stroke care in these areas. Population-based epidemiological studies are crucial to define incidence and prevalence of stroke but are expensive and difficult to implement in a large, heavily populated city as São Paulo. This may explain the paucity of such studies in large urban South American centers. Hospital-based registries can represent the first, less costly step to define specific 
goals for improvement of health care, as supported by the STEPS algorithm?

Efforts to improve stroke services in Brazil have gradually evolved, mortality rates have decreased over the past two decades ${ }^{15}$ and there is an ongoing discussion about the creation of a National Stroke Network ${ }^{16}$, but systematic information on stroke services in urban and rural areas in different regions of this large, heterogeneous country, as in other developing regions ${ }^{17}$, is still lacking. Improved knowledge about current stroke management in Brazil can greatly aid in planning specific strategies to improve prevention and care, hence decreasing overall stroke burden.

\section{REFERENCES}

1. Truelsen T, Heuschmann P, Bonita R, et al. Standard method for developing stroke registers in low-income and middle-income countries: experiences from a feasibility study of a stepwise approach to stroke surveillance (STEPS Stroke). Lancet Neurol 2007;6:134-139.

2. Saposnik G, Del Brutto OH. Stroke in South America: a systematic review of incidence, prevalence, and stroke subtypes. Stroke 2003;34:2103-2107.

3. Lavados PM, Hennis AJ, Fernandes JG, et al. Stroke epidemiology, prevention, and management strategies at a regional level: latin America and the Caribbean. Lancet Neurol 2007;6:362-372.

4. Mansur AP, Souza MFM, Favarato D, et al. Stroke and ischemic heart disease mortality trends in Brazil from 1979 to 1996. Neuroepidemiology 2003;22:179-183.

5 Lotufo PA, Bensenor IM. Trends of stroke subtypes mortality in Sao Paulo, Brazil (1996-2003). Arq Neuropsiquiatr 2005;63:951-955.
6. Lavados PM, Sacks C, Prina L, et al. Incidence, case-fatality rate, and prognosis of ischaemic stroke subtypes in a predominantly HispanicMestizo population in Iquique, Chile (PISCIS project): a communitybased incidence study. Lancet Neurol 2007;6:140-148.

7. IBGE / Censos demográficos, contagem populacional e projeções e estimativas demográficas. Available at: http: / / tabnet.datasus.gov.br/cgi / deftohtm.exe?idb2005/a01.def. Last accessed May $8^{\text {th }}, 2007$.

8. Sudlow CL, Warlow CP. Comparing stroke incidence worldwide: what makes studies comparable? Stroke 1996;27:550-558.

9. Cabral NL, Longo AL, Moro CH, Amaral CH, Kiss HC. [Epidemiology of cerebrovascular disease in Joinville, Brazil: an institutional study]. Arq Neuropsiquiatr 1997;55:357-363.

10. Minelli C, Fen LF, Minelli DPC. Stroke incidence, prognosis, 30-day and 1-year case fatality rates in Matão, Brazil. Stroke 2007;38:2906-2911.

11. Hill MD, Buchan AM. Thrombolysis for acute ischemic stroke: results of the Canadian Alteplase for Stroke Effectiveness Study. CMAJ 2005;172:1307-1312.

12. Katzan IL, Hammer MD, Hixson ED, Furlan AJ, Abou-Chebl A, Nadzam DM. Utilization of intravenous tissue plasminogen activator for acute ischemic stroke. Arch Neurol 2004;61:346-350.

13. Bhalla A, Grieve R, Tilling K, Rudd AG, Wolfe CD. Older stroke patients in Europe: stroke care and determinants of outcome. Age Ageing 2004;33:618-624.

14. Di Carlo A, Lamassa M, Baldereschi M, et al. Sex differences in the clinical presentation, resource use, and 3-month outcome of acute stroke in Europe: data from a multicenter multinational hospital-based registry. Stroke 2003;34:1114-1119.

15. Andre C, Curioni CC, Cunha CB, Veras R. Progressive decline in stroke mortality in Brazil from 1980 to 1982, 1990 to 1992, and 2000 to 2002. Stroke 2006;37:2784-2789.

16. Massaro AR. Stroke in Brazil: a South America perspective. Int J Stroke 2006;1:113-115.

17. Brainin M, Teuschl Y, Kalra L. Acute treatment and long-term management of stroke in developing countries. Lancet Neurol 2007;6:553-561. 